Viso - Cadernos de estética aplicada Revista eletrônica de estética

ISSN 1981-4062

No 19, jul-dez/2016

http://www.revistaviso.com.br/

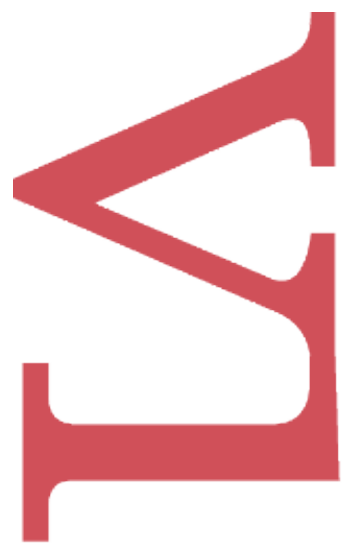

の
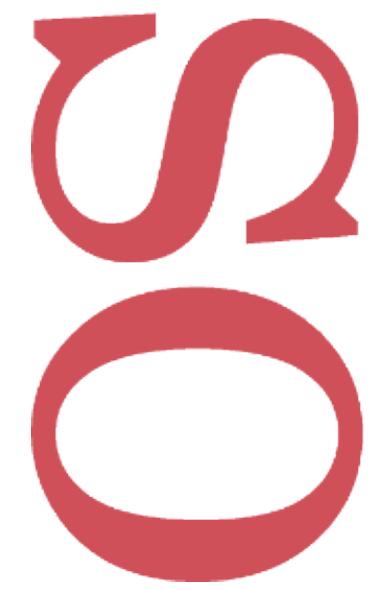

\title{
A experiência estética face ao abjeto Rosa Gabriella
}




\section{RESUMO}

A experiência estética face ao abjeto

Esse artigo é uma réplica ao texto de Verlaine Freitas intitulado "A regressão totêmica pré-trágica em o remorso de baltazar serapião".

Palavras-chave: baltazar serapião - valter hugo mãe - abjeto

\section{ABSTRACT}

Aesthetic Experience Facing the Abject

This paper is a critical response to Verlaine Freitas' "Pre-tragic Totemic Regression in 0 remorso de baltazar serapiao".

Keywords: baltazar serapião - valter hugo mãe - abject 


\section{GABRIELLA, R. "A experiência estética face ao abjeto". In: Viso: Cadernos de estética aplicada, v. X, n. 19 (jul- dez/2016), pp. 233-240.}

DOI: $10.22409 / 1981-4062 / v 19 i / 244$

Aprovado: 28.09.2016. Publicado: 28.12.2016.

(C) 2016 Rosa Gabriella. Esse documento é distribuído nos termos da licença Creative Commons Atribuição-NãoComercial 4.0 Internacional (CC-BY-NC), que permite, exceto para fins comerciais, copiar e redistribuir o material em qualquer formato ou meio, bem como remixá-lo, transformá-lo ou criar a partir dele, desde que seja dado o devido crédito e indicada a licença sob a qual ele foi originalmente publicado.

Licença: http://creativecommons.org/licenses/by-nc/4.0/deed.pt_BR

Accepted: 28.09.2016. Published: 28.12.2016.

(C) 2016 Rosa Gabriella. This document is distributed under the terms of a Creative Commons Attribution-NonCommercial 4.0 International license (CC-BY-NC) which allows, except for commercial purposes, to copy and redistribute the material in any medium or format and to remix, transform, and build upon the material, provided the original work is properly cited and states its license.

License: http://creativecommons.org/licenses/by-nc/4.0/ 
O texto de Verlaine Freitas, "A regressão totêmica pré-trágica em o remorso de Baltazar Serapião" me levou a estabelecer quase que imediatamente um paralelo com aquilo que, nas artes visuais, costumamos denominar abjeto, disturbatório, ou escatológico.

O romance de valter hugo mãe, no qual as personagens femininas são violentadas e mutiladas a cada página é, como bem define Verlaine, "uma poética da violência da regressão, do asco causado por uma barbárie inominável e da fraqueza irremediável de uma cultura cuja impotência somente é páreo à soberba infinita do seu cinismo". Contudo, o texto de Verlaine fornece um anteparo ao choque causado pelo livro: racional, elegante, erudito, distanciado da ferida exposta em carne viva e da miséria insuportável da obra de valter hugo mãe.

Concordo com Verlaine quando este afirma que do ponto de vista da forma trata-se de uma tragédia na qual "o sobrenatural se insere cada vez mais na trama narrativa como indíce de uma regressão mítica e mística no interior do próprio enredo". Temos um herói/ narrador às voltas com sua truncada relação com o destino, sua incapacidade para ler os sinais que desde sempre denunciavam o caráter trágico da sua existência, a ida ao oráculo, o feitiço, enfim, como aponta Verlaine, diversos elementos próximos da concepção clássica, aristotélica, da tragédia, sobretudo, "a tensão dialética entre o destino e a decisão individual", que podemos traduzir pela falência do herói/narrador ao tentar lidar com seu destino trágico, a qual não sabemos se devemos atribuir à passividade ou ao seu caráter cínico, aspecto este perspicazmente captado por Verlaine.

Mas o que pretendo discutir brevemente aqui é a idéia de pré-trágico, que Verlaine percebe no conteúdo, como algo "regressivo, regredido, empurrado para aquém da luta irresolvida pela instauração do sujeito como quem se firma em valores". Esse conteúdo pré-trágico me levou a pensar no "informe", tal como este foi pensado por Bataille e a aproximar o livro de valter hugo mãe do universo da arte contemporânea, sob a ótica do artigo "O retorno do real", no qual Hal Foster nos lembra que no começo dos anos 60, no seminário intitulado "O inconsciente e a repetição", Jacques Lacan havia começado a definir o real em termos do trauma.

Nesse seminário, Lacan define o traumático como um desencontro com o real. Enquanto perdido, o real não pode ser representado; ele só pode ser repetido. De fato ele deve ser repetido. Wiederholen, escreve Lacan em referência etimológica à idéia de repetição em Freud, não é Reproduzieren: repetição não é reprodução. ${ }^{1}$

Foster estava pensando na repetição de imagens traumáticas por Andy Warhol nas suas séries de imagens de acidentes, ou da cadeira elétrica. Acredito que de algum modo também é pela repetição que o real irrompe no livro de hugo mãe. A repetição leva o real a romper com o anteparo que deveria ser causado pela repetição, mas ele é incapaz de se submeter ao simbólico. Daí podermos pensar que a obra de hugo mãe, assim como parte da produção contemporânea nas artes visuais, se recusa a construir uma mediação e nos traz o real sem anteparo. 
Um dos aspectos mais chocantes do livro de hugo mãe, sobre o qual pretendo me debruçar, é o modo como o corpo feminino é constantemente violado e mutilado pelo narrador. Nas palavras de Verlaine,

o feminino é vivido como o que se infiltra em todas as camadas semânticas, como índice de instabilidade, perigo e incompreensão [...] atrai e ao mesmo tempo esconjura, é doce e amargo, angelical e demoníaco, tudo sem a mediação suavizadora da racionalidade progressiva.

Verlaine chama a atenção para o fato de os nascimentos se desdobrarem em mortes e do parto da mãe do narrador, que não chega sequer a ter um nome, ser ao mesmo tempo um assassinato, o que me remete novamente a Foster quando este comenta:

como ocorre frequentemente em filmes de terror e histórias de ninar, o horror significa, em primeiro lugar e acima de tudo, horror à maternidade, ao corpo da mãe tornado estranho, mesmo repulsivo. Esse corpo é igualmente a cena primária do abjeto, uma categoria do (não)ser definida por Julia Kristeva como nem sujeito, nem objeto, mas antes de se tornar o primeiro (antes da inteira separação da mãe) ou depois que se tornou objeto (como um cadáver entregue à condição de objeto). ${ }^{2}$

Nos anos de 1980 e 1990, muitos artistas visuais exploraram ideias de regressão, abjeção e fragmentação do corpo para discutir questões ligadas à sexualidade e à morte. Essa mimese da regressão é bastante forte na arte contemporânea, impondo uma estranha regressão não simplesmente ao infantil, mas até ao inorgânico e, por vezes, ao repulsivo. Artistas já conhecidas nos anos 60 e 70, como Eva Hesse e Louise Bourgeois, tornaram-se ainda mais influentes, neste contexto aberto à exploração do corpo e do espaço modelados psicologicamente por desejos e fantasias.

O conceito de "abjeto" tornou-se recorrente na crítica e na teoria a partir de então. Segundo a definição canônica do abjeto dada por Julia Kristeva: abjeta é uma substância com uma carga psicológica, frequentemente imaginada, que existe entre um sujeito e um objeto; algo ao mesmo tempo estranho e intimidante, que expõe a fragilidade daquele sujeito, bem como uma distinção entre aquilo que the é interior e exterior. Abjeto seria aquilo que nos confronta, por um lado, com aqueles estados frágeis nos quais o homem transita pelo território da animalidade e que provocou nele a necessidade de se destacar desse domínio assustador, frequentemente representado pela morte e pelo sexo e, por outro lado, aquilo que nos confronta e, nesse caso, no interior de nossa arqueologia pessoal, com nossas tentativas mais arcaicas de demarcarmos a entidade materna. ${ }^{3}$

A abjeção é uma condição na qual a subjetividade é perturbada e que se expressa na arte por meio de situações e objetos chocantes, dejetos, detritos e escatologia. Segundo Kristeva, o abjeto é uma condição da qual o sujeito precisa se livrar para poder se tornar sujeito. Uma condição estranha e íntima ao mesmo tempo, próxima demais, que toca na fragilidade de nossos limites, uma espécie de desafio à repressão e à sublimação, tal como estas foram descritas por Freud em $O$ mal estar na civilização, daí o gosto pela 
exibição do fecal e do anal. Esse é o âmbito principal da arte abjeta: expor o corpo violentado.

Kristeva localiza na literatura alguns exemplos nos quais identifica a presença do abjeto, como por exemplo em Ulysses, de James Joyce, onde o corpo feminino aparece como aquilo que não pode ser significado, que não pode ser simbolizado. É no monólogo de Molly Bloom que o escritor se aproxima do corpo histérico, para faze-lo falar, para falar por meio daquele corpo sobre aquilo que escapa ao discurso: um lugar absoluto, pois primordial, um lugar impossível, do excluído, daquilo ao qual não se consegue atribuir sentido. ${ }^{4}$

Podemos estabelecer analogias entre o texto de hugo mãe e certas obras visuais contemporâneas, como por exemplo as esculturas de Kiki Smith nas quais o corpo materno é alvo de um sujeito infantil ambivalente que o estraga e restaura, ou em esculturas nas quais o corpo materno é seccionado, violentado, apresentado como resíduo de algum tipo de violência, trauma ou humilhação. Impossível não pensarmos em ermesinda, a esposa do narrador, que ao longo do livro tem um pé e um braço torcidos, um olho arrancado, uma mão decepada, perde a voz e adquire várias depressões no crânio após ser espancada pelo marido mas que, como bem aponta Verlaine, "carregará a suprema ambiguidade irônica de, mesmo aviltada, permanecer bela". Ao que parece, arrancar ou inutilizar partes do corpo de ermesinda é, para serapião, uma espécie de ritual de purificação, ou de sacrifício.

Para Hal Foster, parte da arte contemporânea explora justamente condições extremas que são sugeridas por cenas de desastres, decadência e morte. Muitas vezes o trauma é reencenado como site, lugar onde memória e fantasia poderiam ser revividas. Tais imagens evocam o corpo virado ao avesso, daí a constatação de que algumas imagens passam para além do abjeto, que frequentemente se relaciona com substâncias e significados não só em direção ao informe segundo Bataille, aquela condição na qual a forma significativa se dissolve porque a distinção fundamental entre figura e fundo ou eu e outro se perde, mas também em direção ao obsceno, em que o olhar-do-objeto é apresentado como se não houvesse uma cena para encená-lo, nenhuma moldura representativa para contê-lo, nenhum anteparo.

Parte da arte dos anos de 1980 e 1990 quer justamente extrapolar a condição sublime e trazer à tona a pulsão e o real. Nesse sentido, podemos pensar na trajetória de Cindy Sherman, sobretudo devido ao fato de a artista sempre ter se debruçado sobre questões relativas ao corpo feminino e ao trauma. Em seu trabalho inicial, entre 1975 e 1982, Sherman mostrou o sujeito feminino supervisionado por si mesmo, algo no estilo "quando me vejo no espelho não sou como eu imaginava", apontando para o fosso existente entre o corpo imaginado, extraído da indústria do entretenimento ou da moda, e o corpo efetivo. 
Na fase intermediária, entre 1987 e 1990, aparecem as fotos de contos de fada, retratos da história da arte e desastres, nas quais, por meio de uma dessublimação radical, Sherman confirma sua guinada para o real: aqui o horror significa, principalmente, o horror ao corpo materno, estranho e até repulsivo, o corpo como lugar do abjeto. Algumas imagens dessas séries vão mesmo além do abjeto, não apenas em direção ao informe, como em direção ao obsceno. Após 1991 esta condição extrema domina seu trabalho, com imagens de guerra e sexo, com órgãos sexuais e excrementos expostos. Há uma erosão do sujeito que também podemos reconhecer em outros artistas do período.

Mas será que o abjeto pode mesmo ser representado? Se o abjeto é o oposto da cultura, como pode ser exposto na cultura? Se ele é aquilo que resiste à forma, como pode ser apresentado? A abjeção pode ser mimetizada? Uma resposta possível consistiria em acreditar que a arte pode se aproximar do abjeto quando se aproxima muito dele e quase que o toca, ou o flagra. Outra opção seria a de afirmar que a arte pode apenas simular, ou mimetizar o abjeto.

Talvez exista uma política cultural na arte abjeta e na sua aspiração a uma regressão ao inorgânico, talvez o êxtase demonstrado por certos artistas contemporâneos com a ruptura do anteparo e da ordem simbólica e o fascínio pelo trauma sejam sintomas do medo que essa ruptura provoca. Essa estética do abjeto parece atender a certos imperativos contemporâneos de fragmentação e descontinuidade, mas não se pode deixar de lembrar que o surrealismo também foi atraído pelo abjeto como forma de testar a sublimação. Aliás, foi nesse ponto que o surrealismo rompeu, dividindo-se nas duas facções dirigidas por André Breton e Bataille. De acordo com Breton, Bataille era um filósofo do excremento e não por acaso a teoria do trauma de Lacan foi influenciada pelo surrealismo...

Acredito que temos no livro de walter hugo mãe este mesmo impulso para destruir o sujeito e rasgar o anteparo, a rejeição de qualquer sublimação e a intenção de evocar o real enquanto tal. Nas palavras de Verlaine, enquanto a vaca se humaniza, as pessoas se desumanizam, enquanto a vaca ocupa o lugar simbólico e literal do humano, a família se reduz a uma animalidade abjeta e repugnante. Não seriam essas condições extremas vividas por estes personagens algo que ultrapassa o abjeto e se insere no informe?

Face à violência do texto de hugo mãe nos permitimos perguntar qual seria a ambição desta estranha abordagem. Seria apenas a de causar repulsa e choque, ou teria ela uma dimensão libertadora? Segundo Verlaine, a única saída que aparece no livro, a única "via de possibilidade de elevação valorativa do ser humano pela arte é sabotada": a única possibilidade de transcendência estética é abortada e seu agente, o irmão do narrador, é por demais frágil, sendo então o artista "retroagido a uma condição animalesca". O grotesco não se converte em sublime, ele continua indigesto. 
* Rosa Gabriella é professora associada do Departamento de História da Arte e Pintura da UFBA.

${ }^{1}$ FOSTER, H. "O retorno do real". In: Concinnitas, Rio de Janeiro, ano 6, v. 1, n. 8 (julho/2005), p. 166.

2 Ibidem, p. 176.

${ }^{3}$ KRISTEVA, J. Pouvoirs de I'horreur. Paris: Seuil, 1980, p. 20.

${ }^{4}$ Ibidem, p. 30. 